\title{
The essential oil of the protected species: Thymus praecox ssp. penyalarensis
}

\author{
José Blanco Salas ${ }^{1 *}$, Trinidad Ruiz Téllez ${ }^{2}$, Francisco María Vázquez Pardo', María José Pérez-Alonso³, María \\ Ángeles Cases Capdevila ${ }^{4}$ \\ ${ }^{1}$ Grupo HABITAT, Departamento de Producción Forestal, Centro de Investigación Finca La Orden - Valdesequera, Consejería de Empleo, Empresa e Innovación, Junta de Extremadura, Km. 372 , 06187 Guadajira \\ (Badajoz), Spain \\ ${ }^{2}$ Grupo de Investigación en Biología de la Conservación, Área de Botánica, Facultad de Ciencias, Universidad de Extremadura, 06071 Badajoz, Spain \\ ${ }^{3}$ Universidad Complutense, Facultad de Biología, Departamento de Biología Vegetal, Botánica, 28040 Madrid, Spain \\ ${ }^{4}$ Departamento de Medio Ambiente, Instituto Nacional de Investigación y Tecnología Agraria y Alimentaria, 28071 Madrid, Spain
}

\section{Abstract}

The essential oil of a protected Spanish species, Thymus praecox ssp. penyalarensis, was firstly analyzed [Gas ChromatographyMass Spectrometry (GC-MS)] from wild populations during the phenological stages of flowering and fruiting. In flowering, the yield was $1.2 \%$, and the major components were identified as thymol (18.5\%), p-cymene (14.6\%), carvacrol (11.6\%), and $\gamma$-terpinene (10.1\%). In fruiting, the yield was $0.9 \%$ and the major components resulted to be $p$-cymene (19.0\%), carvacrol (16.5\%), and borneol (10.5\%). An experimental cultivation of the taxa was made also in order to analyze its essential oil as well. The yield was $1.3 \%$, and the main compounds were thymol (19.1\%), p-cymene (17.0\%), and $\gamma$-terpinene (12.3\%). Finally, the composition of the essential oil of this plant is discussed in relation to chemotaxonomic and biogeographical aspects.

Keywords: endemism, essential oil, GC-MS, threatened species, Thymus praecox ssp. penyalarensis

\section{Introduction}

Most works that have dealt with the chemical composition of essential oils of plants of the genus Thymus (Lamiaceae) have been centred on Thymus vulgaris L., because of its extensive use in many countries as an aromatic and medicinal plant due to its antioxidant, antimicrobial and anti-inflammatory activity [1-3]. Nevertheless, the chemical composition of some species of that genus is practically unknown, in spite of being protected species or endemic plants of interest environmentally. That is the case of Thymus praecox ssp. penyalarensis (Pau) Rivas Martínez, Fernández González \& Sanchez-Mata. This is a thyme that lives exclusively in the highest peaks of the Sierra de Gredos (Sistema Central, Spain) between 1800 and 2400 $\mathrm{m}$ a.s.l., carpeting cracks in siliceous rocks. It is listed in the Catalogue of Threatened Species of the Extremadura Autonomous Community [4] under the category of "Special Interest". On that basis, the present work was undertaken with the aim of contributing the first analysis of its essential oil production and to assess its interest from both the chemotaxonomic and applied points of view.

\footnotetext{
*Corresponding author. Email: pepebsalas@yahoo.es

This is an Open Access digital version of the article distributed under the terms of the Creative Commons Attribution 3.0 License (creativecommons.org/licenses/by/3.0/), which permits redistribution, commercial and non-commercial, provided that the article is properly cited.
}

Material and methods

\section{Plant material}

Several specimens of Th. praecox ssp. penyalarensis were collected at Pico Calvitero, Caceres, Spain (2200 m a.s.l., 30TTK56) in 2004, first in the flowering stage and then in the fruiting stage. Voucher samples (HSS 11842/11843/11848) were deposited in the Herbarium HSS of the La Orden-Valdesequera Research Centre, Extremadura Local Government. On the other hand, seeds were collected from the same population. A germination test was performed under the ISTA [5] protocol. Seedlings were sown to produce an experimental cultivation in the Research Center La Orden, situated in Guadajira, (232 $\mathrm{m}$ a.s.l., 29SPD90), Badajoz, Spain, and several specimens was collected in the flowering stage in 2007.

\section{Isolation of volatile components}

The extraction of the essential oils was carried out by hydrodistillation according to the method proposed by the European Pharmacopoeia [6]. The essential oil sample obtained was used to estimate the essential oil yield $(\mathrm{mL} / 100 \mathrm{~g})$ and to determine its percentage composition.

\section{Gas chromatography (GC)}

The analytical GC was carried out on a Varian 3300 gas chromatograph fitted with a fused methyl silicone DB-1 column ( $50 \mathrm{~m} \times 0.25 \mathrm{~mm}, 0.25 \mu \mathrm{m}$ film thickness). Temperature was programmed from $95^{\circ} \mathrm{C}$ to $240^{\circ} \mathrm{C}$ at $4^{\circ} \mathrm{C} \mathrm{min}{ }^{-1}$. Injection was performed at $250^{\circ} \mathrm{C}$ in the split mode $(1: 100)$. Nitrogen was used as the carrier gas $\left(1.5 \mathrm{~mL} \mathrm{~min}{ }^{-1}\right)$. Flame ionization 
detection (FID) was performed at $300^{\circ} \mathrm{C}$. Injection for all the samples was $0.5 \mu \mathrm{L}$ of $1 \%$ solution of essential oil in diethyl ether, in the split mode (1:100).

\section{Gas chromatography-mass spectrometry (GC-MS)}

GC-MS was carried out on a Hewlett-Packard 5890 gas chromatograph fitted with a fused silica SE-30 capillary column $(50 \mathrm{~m} \times 0.22 \mathrm{~mm}, 0.25 \mu \mathrm{m}$ film thickness), coupled to a HP 5971A mass selective detector. Column temperature was programmed from $70^{\circ} \mathrm{C}$ to $220^{\circ} \mathrm{C}$ at $4^{\circ} \mathrm{C} \mathrm{min}^{-1}$, and helium was used carrier gas. Mass spectra were recorded in the scan mode at $70 \mathrm{eV}$.

Most constituents were tentatively identified by GC by comparison of their retention indices with those of authentic standards available in the author's laboratory or with retention indices in close agreement with references [7-9]. Further identification was achieved by GC/MS. The mass spectral fragmentation patterns were compared with those stored (Wiley built-in library) in the spectrometer data base.

\section{Results}

The chromatograms showed the major components of the essential oil to be, in the flowering stage, thymol (18.5\%), $p$ cymene (14.6\%), carvacrol (11.6\%), and $\gamma$-terpinene (10.1\%). Other components that reached high percentages (in the range 5-10\%) were borneol, sabinene, (E)-caryophyllene, and 1,8-cineol. During the fructification the major components were $p$-cymene (19.0\%), carvacrol (16.5\%), and borneol $(10.5 \%)$. In the range of $5-10 \%$ we found $\gamma$-terpinene, 1,8 -cineol, and sabinene. The percentage of thymol (4.1\%) is much lower than those corresponding to flowering stage (18.5\%) and to cultivated material (19.1\%). The composition varied from flowering to fruiting, as also did the yield, which declined from $1.25 \%$ to $0.94 \%$ (Tab. 1 ).

\section{Discussion}

Many of the components of the thymes essential oils have very interesting biological activities, as is the case of those we found in the greatest proportions in the plant of the present study. In particular, these components were thymol, carvacrol, and $p$-cymene, all of them compounds exhibiting antimicrobial [4], insecticidal [10], anti-inflammatory [11], antispasmodic [12] and antioxidant [13] activities. There is no evidence that this plant has had either medicinal or culinary uses, probably due to the inaccessibility of its natural populations. Due to the chemical composition of this plant, that makes it a potential source of interesting products, and also for its threatened species character, we considered prioritary its domestication. Results obtained in cultivation were satisfactory, for the seedlings had an optimum development in the essay plot, although the climate conditions were clearly warmer than in the original wild population.

Concerning composition, in flowering the chemical composition of the essential oil in the wild material reached values similar to those obtained with cultivated material at the same phenological stage. We must outline that the obtained percentage of carvacrol (3.4\%) in cultivated material was much lower than those corresponding to wild material either at flowering $(11.6 \%)$ or at fruiting (16.5\%) stage. Yield was $1.3 \%$. No significant differences were observed, although carvacrol reached very lower levels in comparison with those obtained from wild material (cultivated 3.4\%; wild 11.6\%).

From a conservation perspective, the knowledge of the phytochemistry of this plant adds to its botanical interest and the importance of its status of legal protection. In this respect we must outline that the compounds of a general pathway for the biosynthesis of aromatic monoterpenes in genus Thymus [14], have a high degree of representation with regard to the total sample analized, with values over $49 \%$ (Tab. 2 ). We can highlight that $p$-cymene, the main precursor of the oxygenated

Tab. 1 Percentage oil composition and yield of the essential oil of Th. praecox ssp. penyalarensis.

\begin{tabular}{|c|c|c|c|c|c|}
\hline \multirow[b]{2}{*}{ Compound } & \multirow[b]{2}{*}{$R I$} & \multirow[b]{2}{*}{$R T M$} & \multicolumn{2}{|c|}{ Wild plant } & \multirow{2}{*}{$\begin{array}{l}\text { Cultivated plan } \\
\text { Flowering stage }\end{array}$} \\
\hline & & & Flowering stage & Fruiting stage & \\
\hline$\alpha$-thujene & 926 & 4.93 & 0.7 & 1.0 & 1.7 \\
\hline a-pinene & 933 & 5.07 & 2.3 & 2.8 & 3.1 \\
\hline camphene & 952 & 5.32 & 3.2 & 4.8 & 3.9 \\
\hline sabinene & 985 & 5.66 & 6.5 & 5.7 & 6.2 \\
\hline$\beta$-pinene & 990 & 5.79 & 1.8 & 1.3 & 1.2 \\
\hline myrcene & 995 & 5.93 & 0.3 & 0.2 & 0.4 \\
\hline 3-octanol & 999 & 5.93 & 0.9 & 1.1 & 1.5 \\
\hline a-phellandrene & 1007 & 6.19 & 0.3 & 0.2 & 0.4 \\
\hline d-3-carene & 1012 & 6.3 & $t$ & $t$ & 0.1 \\
\hline a-terpinene & 1018 & 6.41 & 2.7 & 2.3 & 5.8 \\
\hline$p$-cymene & 1020 & 6.59 & 14.6 & 19.0 & 17.0 \\
\hline limonene & 1027 & 6.65 & 1.1 & 1.5 & 2.1 \\
\hline$\beta$-phelandrene & 1027 & 6.65 & 1.9 & 3.8 & 3.3 \\
\hline 1,8-cineol & 1028 & 6.74 & 5.2 & 9.1 & 5.6 \\
\hline (Z)- $\beta$-ocimene & 1039 & 6.9 & 0.8 & 1 & 1.2 \\
\hline$\gamma$-terpinene & 1050 & 7.23 & 10.1 & 9.2 & 12.3 \\
\hline cis-sabinene hydrate & 1062 & 7.37 & 0.8 & 0.2 & 0.2 \\
\hline terpinolene & 1080 & 7.77 & $t$ & $t$ & $t$ \\
\hline linalool & 1122 & 7.93 & 0.2 & $t$ & 0.4 \\
\hline camphor & 1151 & 9.01 & $t$ & 0.1 & 0.2 \\
\hline
\end{tabular}




\begin{tabular}{|c|c|c|c|c|c|}
\hline \multirow[b]{2}{*}{ Compound } & \multirow[b]{2}{*}{$R I$} & \multirow[b]{2}{*}{$R T M$} & \multicolumn{2}{|c|}{ Wild plant } & \multirow{2}{*}{$\begin{array}{c}\text { Cultivated plan } \\
\text { Flower stage }\end{array}$} \\
\hline & & & Flowering stage & Fruiting stage & \\
\hline terpinen-4-ol & 1194 & 9.7 & $t$ & $t$ & 0.1 \\
\hline p-cymen-8-ol & 1199 & 9.8 & $t$ & $t$ & 0.1 \\
\hline a-terpineol & 1216 & 9.95 & 0.3 & $t$ & 0.5 \\
\hline thymyl-methyl ether & 1246 & 11.05 & 0.2 & 0.1 & 0.6 \\
\hline carvone & 1252 & 11.46 & $t$ & $t$ & $t$ \\
\hline p-cymen-7-ol & 1290 & 11.92 & $t$ & $t$ & $t$ \\
\hline thymol & 1295 & 12.26 & 18.5 & 4.1 & 19.1 \\
\hline carvacrol & 1309 & 12.46 & 11.6 & 16.5 & 3.4 \\
\hline a-terpenyl acetate & 1359 & 13.19 & 0.1 & $t$ & 0.3 \\
\hline thymyl acetate & 1365 & 13.44 & 0.2 & $t$ & 0.1 \\
\hline carvacryl acetate & 1381 & 13.83 & $t$ & 0.5 & $t$ \\
\hline (E)-caryophyllene & 1418 & 15.06 & 5.3 & 3.8 & 3.2 \\
\hline a-trans-bergamotene & 1434 & 15.22 & $t$ & $t$ & 0.1 \\
\hline aromadendrene & 1440 & 15.41 & $t$ & $t$ & $t$ \\
\hline$(Z)$ - $\beta$-fernesene & 1445 & 15.55 & $t$ & $t$ & $t$ \\
\hline a-humulene & 1458 & 15.7 & 0.3 & 0.1 & 0.2 \\
\hline (E)- $\beta$-fernesene & 1461 & 15.78 & $t$ & $t$ & $t$ \\
\hline allo-aromadendrene & 1465 & 15.86 & $t$ & $t$ & 0.1 \\
\hline germacrene D & 1503 & 16.09 & $t$ & $t$ & $t$ \\
\hline germacrene A & 1497 & 16.57 & 0.2 & $t$ & 0.1 \\
\hline$\beta$-bisabolene & 1511 & 16.71 & 1.5 & 0.8 & 0.6 \\
\hline$\beta$-sesquiphellandrene & 1520 & 17.01 & 0.2 & $t$ & 0.1 \\
\hline spathulenol & 1575 & 18.19 & $t$ & $t$ & 0.2 \\
\hline epi- $\alpha$-mouurolol & 1639 & 19.31 & 0.1 & $t$ & $t$ \\
\hline Essential oil yield (mL/100 g) & & & 1.2 & 0.9 & 1.3 \\
\hline
\end{tabular}

$R I$ - retention index according to $n$-paraffins on DB-1 column; $R T M$ - retention time in GLC-MS; $t$ - trace $(<0.1 \%)$.

derivatives, has been transformed in thymol and carvacrol on flowering more easily in the field (wild material) than under cultivation.

From the biogeographical point of view, we must emphasize that within the Th. praecox species there exist several subspecies. In the northernmost zones of Europe, reaching up to the Arctic Circle, there exist Th. praecox ssp. arcticus (E. Durand), Jalas. This differs from the rest in the type of pilosity and the size of the leaves and calyx [15]. Its essential oil polymorphism has been studied, and different number of chemotypes have been described on material from Britain, Iceland, Greenland, and Norway [16-20], revealing that this polymorphism is more distinctive in the southern than in the northern regions. The most frequent chemotypes were the acyclic monoterpenic ones: hedycarol, linalool/linalyl acetate, germacra-1(10),4dien-6-ol. Opposite to this, the other published cases of subspecies from the more southerly latitudes of the zones around the Mediterranean sea present a higher frequency of phenolic monoterpenes ( $p$-cymene, thymol, carvacrol) - a situation that is similar to that found in the present work. For example, in the mountains of Central and Southern Europe, there exists Th. praecox ssp. polytrichus A. Kerner ex Borb Jalas, similar to the previous subspecies, except for some differences in the size of the cauline leaves [15]. Bischof-Deichnik et al. [21], in an analysis of samples from 16 sites in the Austrian and Italian
Alps, found 12 types of oils, with the thymol type being the most frequent.

Th. praecox ssp. skorpilii (Velen.) Jalas is a subspecies of the Northern and Central Balkans in which various morphological varieties have been described $[15,22]$ that coincide with differences in chemical composition and geographic distribution. Baser et al. [23] studied its essential oil in Turkey. The var. laniger, endemic of C. Anatolia, with villous leaves, had high percentages of thymol (7.75-41.38\%) and carvacrol (7.64$10.51 \%)$. The var. skorpilii, which has a somewhat broader area of distribution and glabrous leaves, showed high percentages of geraniol (24.21\%) a-terpinyl acetate $(22.67 \%)$, and geranyl acetate $(9.31 \%)$.

Another close subspecies studied by Baser et al. [23] was Th. praecox ssp. grossheimii var. grossheimii, for which high percentages were found for thymol (26.64\%) and $p$-cymene $(24.88 \%)$. This is a thyme that lives in Northeastern and Southeastern Anatolia, the Caucasus, and Northwestern Iran, and differs from the foregoing in the shape and size of the basal and cauline leaves [22].

The subspecies studied in Turkey and the Alps, and also those ones analyzed in the present work, belong to zones of the world with a Mediterranean-type macrobioclimate [24], in spite of being found in the highest zones of great mountain ranges (Oromediterranean subtype). The Arctic subspecies, 
Tab. 2 Compounds involved in the biosynthetic pathway of aromatic monoterpenes in Th. praecox ssp. penyalarensis.

\begin{tabular}{lccc} 
& \multicolumn{2}{c}{ Wild plant } & Cultivated plant \\
\cline { 2 - 4 } Compound & Flowering stage & Fruiting stage & Flowering stage \\
\hline -cymene & 14.6 & 19.0 & 17.0 \\
$\gamma$-terpinene & 10.1 & 9.2 & 12.3 \\
$p$-cymen-8-ol & $t$ & $t$ & 0.1 \\
thymyl-methyl ether & 0.2 & 0.1 & 0.6 \\
$p$-cymen-7-ol & $t$ & $t$ & $t$ \\
thymol & 18.5 & 4.1 & 19.1 \\
carvacrol & 11.6 & 16.5 & 3.4 \\
thymyl acetate & 0.2 & $t$ & 0.1 \\
carvacryl acetate & $t$ & 0.5 & $t$ \\
Total & 55.2 & 49.4 & 52.5 \\
\hline
\end{tabular}

$t-\operatorname{trace}(<0.1 \%)$.

located in temperated to circumpolar zones, is adapted to temperated to extreme cold year round, with a temperated to boreal macrobioclimate.

The Mediterranean macrobioclimate is not only warmer than the temperated or boreal, but also involves summer drought and a greater degree of climatic variation over the course of the year. Over the course of evolution, this could have represented a selective pressure that may be related to the variability of chemotypes in the Mediterranean subspecies, dominating the phenolic terpenes chemotypes. That contrasts with the chemotype variability of the temperated or boreal zones, which are less climatically variable over the course of the year and have not adaptions to support summer droughts, as is typical in the Mediteranean.

Essential oil polychemismus is a widespread phenomenon in the genus Thymus all over the continent [25], and from the foregoing, it can be derived that the chemical composition, which has been described here for the first time, has biological, taxonomic, and evolutionary significance, and represents a new opportunity to consider plants as both heritage and resource.

\section{Acknowledgements}

This work was partly supported by the Instituto Nacional de Investigación y Tecnología Agraria y Alimentaria (INIA) (RF00-019-C2-2) and the Fundación para el Desarrollo de la Ciencia y la Tecnología de Extremadura (FUNDECYT; PRI-III 3PRO5A043). Authors wish to thank the helpful collaboration of Jesús Sanz (Centro de Química Orgánica "Manuel LoraTamayo" C.S.I.C.) and R. Chatwin for the translation of the original manuscript.

\section{References}

1. Miura K, Kikuzaki H, Nakatani N. Antioxidant activity of chemical components from sage (Salvia officinalis L.) and thyme (Thymus vulgaris L.) measured by the oil stability index method. J Agric Food Chem. 2002;50(7):1845-1851. http://dx.doi.org/10.1021/jf011314o

2. Pina-Vaz C, Goncalves Rodrigues A, Pinto E,
Costa-de-Oliveira S, Tavares C, Salgueiro L, et al. Antifungal activity of Thymus oils and their major compounds. J Eur Acad Dermatol Venereol. 2004;18(1):73-78. http:// dx.doi.org/10.1111/j.1468-3083.2004.00886.x

3. Vigo E, Cepeda A, Gualillo O, Perez-Fernandez R. In-vitro anti-inflammatory effect of Eucalyptus globulus and Thymus vulgaris: nitric oxide inhibition in J774A.1 murine macrophages. J Pharm Pharmacol. 2004;56(2):257-263. http:// dx.doi.org/10.1211/0022357022665

4. Diario Oficial de Extremadura. Ordinance 37/2001, 6th march, by which it is regulated the regional checklist of dangered species of Extremadura, numer 30, 11th march 2001 [Internet]. 2001 [cited 2010 Mar 13]; Available from: http://doe.juntaex.es/pdfs/doe/2001/300O/01040040.pdf

5. International Seed Testing Association (ISTA). International rules for seed testing. Seed Sci Technol. 1999;27 suppl:1-333.

6. European Pharmacopoeia. 3rd ed. Strasbourg: Council of Europe; 1996.

7. Adams RP. Identification of essential oil components by gas chromatography - mass spectrometry. Carol Stream IL: Allured Publishing Corporation; 2007.

8. Joulain D, König WA. The atlas of spectral data of sesquiterpene hydrocarbons. Hamburg: E. B. Verlag; 1998.

9. Swigar AA, Silverstein RM. Monoterpenes. Milasauki WI: Aldrich; 1981.

10. Hierro I, Valero A, Pérez P, González P, Cabo MM, Montilla MP, et al. Action of different monoterpenic compounds against Anisakis simplex s.l. L3 larvae. Phytomedicine. 2004;11(1):77-82. http://dx.doi. org/10.1078/0944-7113-00375

11. Azuma Y, Ozasa N, Ueda Y, Takagi N. Pharmacological studies on the anti-inflammatory action of phenolic compounds. J Dent Res. 1986;65(1):53-56. http://dx.doi.org/1 $0.1177 / 00220345860650010901$

12. Astudillo A, Hong E, Bye R, Navarrete A. Antispasmodic activity of extracts and compounds of Acalypha phleoides Cav. Phytother Res. 2004;18(2):102-106. http://dx.doi. org/10.1002/ptr.1414

13. Kim DO, Lee CY. Comprehensive study on vitamin C equivalent antioxidant capacity (VCEAC) of various polyphenolics in scavenging a free radical and its structural relationship. Crit Rev Food Sci Nutr. 2004;44(4):253-273. http://dx.doi.org/10.1080/10408690490464960

14. Porter JW, Spurgeon SL, editors. Biosynthesis of isoprenoid compounds. Chichester: Wiley and Sons; 1981. (vol 1).

15. Jalas J. Thymus L. In: Tutin TG, Heywood VH, Burges NA, Moore DM, Valentine DH, Walters SM, et al., editors. Flora Europaea. Cambridge: Cambridge University Press; 1972. p. 172-182. (vol 3).

16. Stahl E. Studi zur Variabilität des ätherischen Öls aus Thymus praecox Opiz ssp. arcticus (E. Dudand) Jalas isländischer Vorkommen. Berichte aus der Forschungsstelle Nodri Ás, Hveragerdi (Island). 1982;38:3-69.

17. Stahl E. The essential oil from Thymus praecox ssp. arcticus growing in Iceland. Planta Med. 1984;50(2):157-160. http:// dx.doi.org/10.1055/s-2007-969659

18. Stahl E. Chemical polymorphism of essential oil in Thymus praecox ssp. arcticus (Lamiaceae) from Greenland. Nord J Bot. 1984;4(5):597-600. http://dx.doi. org/10.1111/j.1756-1051.1984.tb01985.x

19. Stahl-Biskup E. The essential oil from norwegian Thymus species. I. Thymus praecox ssp. arcticus. Planta Med. 
1986;52(1):36-38.

20. Schmidt A, Bischof-Deichnik C, Stahl-Biskup E. Essential oil polymorphism of Thymus praecox subsp. arcticus on the British Isles. Biochem Syst Ecol. 2004;32(4):409-421. http:// dx.doi.org/10.1016/j.bse.2003.10.003

21. Bischof-Deichnik C, Holtuijzen J, Stahl-Biskup E. Multivariate statistical analysis of the essential oil composition of Thymus praecox Opiz ssp. polytrichus (Kern. ex Borb.) Ronn. collected in the Tyrolean Alps. Flavour Frag J. 2000;15(1):1-6. http://dx.doi.org/10.1002/(SICI)10991026(200001/02)15:1<1::AID-FFJ845>3.0.CO;2-8

22. Jalas J. Thymus L. In: Davis PH, editor. Flora of Turkey.
Edinburgh: Edinburgh University Press; 1982. p. 349-382. (vol 7).

23. Baser KHC, Kirimer N, Ermin N, Ozek T, Tumen G. Composition of essential oils from three varieties of Thymus praecox Opiz growing in Turkey. J Essent Oil Res. 1996;8:319-321.

24. Rivas-Martínez S, Penas A, Diaz TE. Bioclimatic map of Europe, bioclimates. León: Cartographic Service, University of León; 2004.

25. Sáez F, Stahl E. Essential oil polymorphism in the genus Thymus. In: Sáez F, Stahl E, editors. Thyme - the genus Thymus. London: Taylor \& Francis; 2002. p. 125-143. 